\title{
The relationship between chemerin, bone metabolism, the RANKL/RANK/OPG system, and bone mineral density in girls with anorexia nervosa
}

\author{
Zofia Ostrowska ${ }^{(1)}$, Małgorzata Morawiecka-Pietrzak ${ }^{\circledR 2}$, Wojciech Pluskiewicz ${ }^{(1)}{ }^{3}$, \\ Elżbieta Świętochowska ${ }^{\mathbb{1} 1}$, Joanna Strzelczyk ${ }^{\circledR 1}$, Karolina Gołąbek ${ }^{\circledR 1}$, Jadwiga Gaździcka ${ }^{(1}$, \\ Katarzyna Ziora (D)2 \\ ${ }^{1}$ Department of Medical and Molecular Biology, Faculty of Medical Sciences in Zabrze, Medical University of Silesia, Katowice, \\ Poland \\ ${ }^{2}$ Department of Paediatrics, Faculty of Medical Sciences in Zabrze, Medical University of Silesia, Katowice, Poland \\ ${ }^{3}$ Department and Clinic of Internal Diseases, Diabetology, and Nephrology, Metabolic Bone Diseases Unit, Faculty of Medical Sciences \\ in Zabrze, Medical University of Silesia, Katowice, Poland
}

\begin{abstract}
Introduction: Based on recent studies in humans, chemerin has been classified as an adipokine that might be associated with osteoporosis and BMD. Bone loss is common in adolescents with anorexia nervosa (AN). Moreover, dysfunction in the production of chemerin has also been shown. Therefore, we carried out a comparative analysis between chemerin, bone metabolism, the RANKL/RANK/OPG system, and BMD in girls with AN.

Material and methods: Plasma chemerin, OC, CTx, OPG, and sRANKL were determined by ELISA in 75 girls with AN aged 12.6-17.8 years. BMD was assessed by DXA and expressed as Z-score according to the lumbar spine (s) and total body (TB) sites. According to the s-BMD- and TB-BMD Z-score, girls with AN were divided into two subgroups with parallel analyses used: normal (Z-score $>-2.0)$ and low (Z-score $\leq-2.0)$ s-BMD, and normal (Z-score $>-2.0$ ) and low (Z-score $\leq-2.0)$ TB-BMD.

Results: Mean OC and the OPG/sRANKL ratio were markedly lower in the low s-BMD subgroup compared to the normal s-BMD subgroup. The s-Z-score values (both low and normal) correlated significantly and positively with the OPG/sRANKL ratio. Only in the low s-BMD subgroup did chemerin correlate significantly and positively with all nutritional indices and the OPG/sRANKL ratio. In the low TB-BMD subgroup the mean OC and the OPG/sRANKL ratio were lower than in the normal TB-BMD subgroup. The TB-Z-score values (both normal and low) correlated significantly and positively with all nutritional indices and the OPG/sRANKL ratio. The low TB-Z-score values correlated significantly and positively also with chemerin. In the low TB-BMD subgroup chemerin correlated significantly and positively with weight and BMI (expressed as absolute values), Cole index, the duration of the disease, and OPG/sRANKL ratio while its correlation with age was negative.

Conclusions: Undernutrition and associated deficit of adipose tissue may result in inadequate chemerin production and skeletal disorders in girls with AN. Chemerin acts as a coordinator of the dynamic balance between bone metabolism and the OPG/RANK/RANKL system and, in turn, may contribute to the loss of bone mass in girls with AN. The cortical bone site seems to be more severely responsive to chemerin actions than the trabecular bone site. (Endokrynol Pol 2022; 73 (1): 26-34)
\end{abstract}

Key words: anorexia nervosa; osteocalcin; CTx; RANKL; OPG; RANK; BMD

\section{Introduction}

Anorexia nervosa (AN) leads to low bone mineral density (BMD), impaired bone quality, and increased risk of fractures [1-6]. Important determinants contributing to decreased BMD are, first of all, low lean mass, hypogonadism, IGF-1 deficiency, and hormonal imbalances (including hormones secreted by adipose tissue - adipokines) that affect bone health. Weight gain, especially of lean body mass, and menses restoration are critical for improving bone outcomes in patients with AN [2-21]. AN can have effects on bone health, particularly during adolescence, when bone mineral mass accrual is a major determinant of peak bone mass [1-9]. It has been well-established that adult women and adolescent girls with AN differ in patterns of biochemical markers of bone turnover $[1,2,7,8,10]$. Women with AN show a decrease in bone formation and an increase in bone resorption markers, consistent with an uncoupling of bone turnover leading to impaired bone metabolism $[7,8,10]$. Adolescent girls with AN, on the other hand, have low turnover rates with decreases in bone formation and resorption markers [7, 8, 10, 11, 18, 19, 21-24]. It has also been found that the receptor activator of 
nuclear factor- $\kappa \mathrm{B}$ ligand/receptor activator of the nuclear factor- $\kappa \mathrm{B} /$ osteoprotegerin (RANKL/RANK/OPG) system might play an important role in the regulation of bone metabolism [18, 19, 22-27]. Both cortical and trabecular bone sites become affected in girls with AN [28-34]. However, the results regarding each of these compartments are not always unequivocal.

Adipokines (e.g. leptin, adiponectin, and chemerin) are biochemical components involved in the modulation of bone remodelling, marrow adipogenesis, and energy metabolism. Metabolic and nutritional diseases such as diabetes mellitus and AN greatly affect marrow adipose tissue quality and quantity as well as bone strength [35]. According to some authors, impaired production, release, and action of adipokines, such as leptin, adiponectin, resistin, visfatin, apelin, vaspin, omentin [5, 8, 10-18, 23, 24, 27], and maybe chemerin [36], may lead to BMD decrease or, alternatively, a lack of the BMD increase expected in adolescence. It is highly probable that the above-mentioned adipokines have an adverse effect on bone tissue via a shift in the OPG/RANKL ratio toward a functional excess of RANKL [18, 22-24, 27].

Experimental data showed that chemerin and its natural receptor CMKLR1 may play an important role in osteoblastogenesis, bone mineralization, and inhibition of osteoclastogenesis [36-39]. Several studies in humans have investigated the relationship between chemerin and bone status [40-46]. However, study populations differed considerably, which makes a comparison of the results difficult. Chemerin levels were found to be higher [40-42,44-46] or lower [43] in patients with osteoporosis than in the control group. All the above-mentioned authors indicated an inverse association between chemerin and BMD [40-42, 44-46].

Leoni et al. [47] suggest that plasma chemerin levels can represent a sensitivity parameter of nutritional status that reflects changes in the level of body fat in children and adolescents with obesity and anorexia nervosa. Oświęcimska et al. [48] found that adolescent girls suffering from AN revealed significantly lower levels of chemerin compared to healthy and obese individuals. It is also known that one of the consequence of AN is a decrease in BMD or lack of an adequate bone mass accrual [3-6, 8-13, 28-30]. To the best of our knowledge, the association between chemerin and bone health has not been evaluated in adolescent girls with AN. Therefore, we hypothesized that in girls with AN there would be an adverse relationship between chemerin, bone metabolism (especially via the RANKL/RANK/OPG system), and BMD. To examine this hypothesis, we examined the association between chemerin and biochemical markers of bone turnover in girls with AN and carried out a comparative analysis between adolescents with normal and low s- and TB-BMD.

\section{Material and methods}

The study comprised 75 adolescent girls aged $12.6-17.8$ years with the restrictive type of AN according to the DSM- 5 diagnostic criteria [24, 49, 50], hospitalized at the Paediatric Endocrinology Ward, Independent Public Clinical Hospital No. 1 in Zabrze, Medical University of Silesia in Katowice (Poland). The average disease duration was 3-51 months. All examined patients were at IV-V Tanner puberty stage and had secondary amenorrhoea of 4-28 months' duration. The initial results of additional laboratory tests excluded those with hepatic and renal dysfunction. Girls with any organic or other psychiatric disorders that could cause cachexia were excluded from the study. On recruitment, no patients were taking medications known to affect the nutritional and bone status (e.g. glucocorticoids, oestrogens, thyroid hormone, or calciumcontaining drugs). During hospitalization, patients were placed on bed rest, which is the standard care. On the day of examination none of the girls presented symptoms of acute infection. The control group comprised 42 age-matched, healthy, regularly menstruating adolescent girls with no endocrine or other disorders that might influence adipose and bone tissue metabolism.

The study was approved by the Bioethics Committee at the Medical University of Silesia in Katowice (No. L.dz. Nr KNW/0022/ KB1/10/I/16); written informed consent was obtained from all examined participants and their parents or legal guardians before participation.

\section{Anthropometric measurements}

The height [m] of all participants was measured using a single stadiometer, weight $[\mathrm{kg}]$ was assessed on a standing electronic scale, and body mass index (BMI) was calculated as weight divided by squared height $\left[\mathrm{kg} / \mathrm{m}^{2}\right]$. Weight and BMI were expressed as absolute values and in the form of standard deviation score (SDS) [51]. The Cole index was also calculated.

\section{Biochemical analysis}

All blood samples were collected after a 12-hour overnight fast, between 8.00 and $9.00 \mathrm{a} . \mathrm{m}$. on the first day of hospital stay. Plasma samples were frozen at $-70^{\circ}$ until the time of assay. Determination of chemerin, osteocalcin (OC), C-terminal telopeptide of type I collagen $\alpha 1$ chain (CTx), OPG, and sRANKL were performed by ELISA using the following kits: chemerin — BioVendor (Czech Republic), OC - MicroVue (USA), CTx - Immunodiagnostic System (IDs) Inc. (USA), OPG and sRANKL — Biomedica GmbH \& Co KG (Austria). The respective intra-assay and inter-assay coefficients of variability were as follows: chemerin: $0.1 \mu \mathrm{g} / \mathrm{L}, 6.1 \%$ and $7.5 \%$; OC: $0.08 \mu \mathrm{mol} / \mathrm{L}$, $7.6 \%$ and $7.4 \%$; CTx: $0.14 \mathrm{nmol} / / \mathrm{L}, 2.5 \%$ and $6.7 \%$; OPG: $0.07 \mathrm{pmol} / \mathrm{L}$, $2.5 \%$ and $4 \%$; sRANKL: $0.09 \mathrm{pmol} / \mathrm{L}, 5 \%$ and $7 \%$.

\section{Bone mineral density}

In girls with AN BMD was assessed by dual-energy X-ray absorptiometry in the first two weeks of hospital stay. Measured sites were lumbar spine and total body, and measurements were performed with Hologic Explorer (USA), compared to the reference population, and expressed as Z-scores. The coefficient of variation (\% CV $=[\mathrm{SD} /$ mean $] \times 100)$ for BMD measurements was $1.1 \%$ for lumbar spine (s) and $0.6 \%$ for total body (TB). Patients were divided into two subgroups with parallel analyses - according to the TB-BMD criterion and the s-BMD criterion: normal (Z-score $>-2.0, n=63$ ) and low ( $Z$-score $\leq-2.0, n=12$ ) s-BMD subgroups as well as normal ( $Z$-score $>-2.0, n=45)$ and low $(Z$-score $\leq-2.0, n=28)$ TB-BMD subgroups. The lack of BMD results in the control group is due to the fact that the parents of healthy girls did not agree for a DXA examination because of radiation. 


\section{Statistical analysis}

The database was prepared using Excel 2016 (Microsoft corporation). Statistical analysis was carried out with Statistica 13.3 for Windows (StatSoft Inc., USA). The results were provided as mean \pm standard deviation (mean $\pm \mathrm{SD}$ ). The normality of the distribution of the study sample was assessed by the Shapiro-Wilk test; homogeneity of variance was computed using Leven's test. In the case of normal distribution of variables, the significance between groups and individual AN subgroups was tested by Student's t-test. In the case of non-normal distribution of variables, the significance was tested using the Mann-Whitney U test. Osteocalcin, sRANKL, and the OPG/sRANKL ratio distribution were not normal, and the low number of patients (especially in Z-score $\leq-2.0$ s-BMD subgroup) was noted, so Spearman's correlation test was used to assess the relationships between BMD at various skeletal sites, clinical and anthropometric parameters, biochemical markers of bone turnover and chemerin. Statistical significance was set at $\mathrm{p}<0.05$.

\section{Results}

Table 1 shows the baseline characteristics, mean plasma chemerin, and biochemical markers of bone turnover levels in individual subgroups of girls with AN and the

Table 1. Clinical characteristic, mean plasma levels of chemerin, and biochemical markers of bone turnover in subgroups of girls with anorexia nervosa $(A N)$ and normal (Z-score $>-2.0)$ and low (Z-score $\leq-2.0)$ bone mineral density of lumbar spine (s-BMD) and bone mineral density of total body (TB-BMD)

\begin{tabular}{|c|c|c|c|c|c|c|c|c|c|c|c|}
\hline \multirow[b]{2}{*}{ Variables } & \multicolumn{2}{|c|}{ s-BMD } & \multicolumn{3}{|c|}{$\mathbf{p}$} & \multicolumn{2}{|c|}{ TB-BMD } & \multicolumn{3}{|c|}{$\mathbf{p}$} & \multirow[b]{2}{*}{$\begin{array}{c}\text { Control } \\
\text { group } \\
\text { (C) } \\
\text { (n = 42) }\end{array}$} \\
\hline & $\begin{array}{c}\text { Normal } \\
\text { Z-score } \\
>-2.0 \\
(n=63)\end{array}$ & $\begin{array}{c}\text { Low } \\
\text { Z-score } \\
\leq-2.0 \\
(n=12)\end{array}$ & 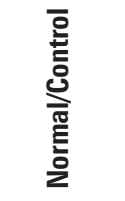 & 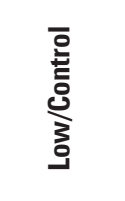 & 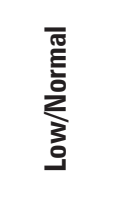 & $\begin{array}{c}\text { Normal } \\
\text { Z-score } \\
>-2.0 \\
(n=47)\end{array}$ & $\begin{array}{c}\text { Low } \\
\text { Z-score } \\
\leq-2.0 \\
(n=28)\end{array}$ & 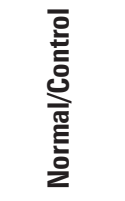 & 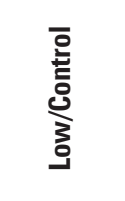 & 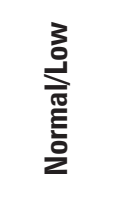 & \\
\hline Age [years] & $\begin{array}{c}15.07 \pm \\
1.33\end{array}$ & $\begin{array}{c}15.30 \pm \\
1.49\end{array}$ & 0.048 & 0.282 & 0.571 & $\begin{array}{c}15.16 \pm \\
1.34\end{array}$ & $\begin{array}{c}15.05 \pm \\
1.36\end{array}$ & 0.054 & 0.066 & 0.637 & $\begin{array}{c}15.87 \\
\pm 1.02\end{array}$ \\
\hline Heigh [m] & $\begin{array}{c}1.63 \pm \\
0.06\end{array}$ & $\begin{array}{c}1.59 \pm \\
0.05\end{array}$ & 0.444 & 0.055 & 0.053 & $\begin{array}{c}1.63 \pm \\
0.06\end{array}$ & $\begin{array}{c}1.60 \pm \\
0,06\end{array}$ & 0.473 & 0.056 & 0.057 & $\begin{array}{c}1.64 \pm \\
0.07\end{array}$ \\
\hline Weight [kg] & $\begin{array}{c}39.96 \pm \\
5.39 *\end{array}$ & $\begin{array}{l}34.42 \pm \\
6.81 * \wedge\end{array}$ & $<0.001$ & $<0.001$ & 0.002 & $\begin{array}{c}39.90 \pm \\
5.52^{*}\end{array}$ & $\begin{array}{c}37.81 \pm \\
6.74^{*}\end{array}$ & $<0.001$ & $<0.001$ & 0.158 & $\begin{array}{c}56.68 \pm \\
8.35\end{array}$ \\
\hline Weight-SDS & $\begin{array}{c}-2.38 \pm \\
1.00^{*}\end{array}$ & $\begin{array}{l}-3.40 \pm \\
0.90^{*} \wedge\end{array}$ & $<0.001$ & $<0.001$ & 0.001 & $\begin{array}{c}-2.35 \pm \\
1.06^{*}\end{array}$ & $\begin{array}{c}-2.72 \pm \\
1.07^{*}\end{array}$ & $<0.001$ & $<0.001$ & 0.155 & $\begin{array}{c}0.34 \pm \\
1.49\end{array}$ \\
\hline BMI $\left[\mathrm{kg} / \mathrm{m}^{2}\right]$ & $\begin{array}{c}15.01 \pm \\
1.59 *\end{array}$ & $\begin{array}{c}13.62 \pm \\
2.20^{*}\end{array}$ & $<0.001$ & $<0.001$ & 0.058 & $\begin{array}{c}14.89 \pm \\
1.54^{*}\end{array}$ & $\begin{array}{c}14.62 \pm \\
2.03^{*}\end{array}$ & $<0.001$ & $<0.001$ & 0.523 & $\begin{array}{c}21.08 \pm \\
2.66\end{array}$ \\
\hline BMI-SDS & $\begin{array}{c}-2.81 \pm \\
0.92^{*}\end{array}$ & $\begin{array}{l}-3.68 \pm \\
1.06^{*} \wedge \\
\end{array}$ & $<0.001$ & $<0.001$ & 0.003 & $\begin{array}{c}-2.80 \pm \\
0.95^{*}\end{array}$ & $\begin{array}{c}-3.55 \pm \\
1.04^{*} \# \\
\end{array}$ & $<0.001$ & $<0.001$ & 0.002 & $\begin{array}{c}0.34 \pm \\
1.52 \\
\end{array}$ \\
\hline $\begin{array}{l}\text { Cole index } \\
(\%)\end{array}$ & $\begin{array}{c}75.19 \pm \\
8.37^{*}\end{array}$ & $\begin{array}{l}65.73 \pm \\
6.27^{*} \wedge\end{array}$ & $<0.001$ & $<0.001$ & $<0.001$ & $\begin{array}{c}74.77 \pm \\
8.80^{*}\end{array}$ & $\begin{array}{l}61.91 \pm \\
10.17^{*} \#\end{array}$ & $<0.001$ & $<0.001$ & $<0.001$ & $\begin{array}{c}102.91 \\
\pm 13.98\end{array}$ \\
\hline $\begin{array}{l}\text { Disease } \\
\text { duration } \\
\text { [months] }\end{array}$ & $\begin{array}{c}12.16 \pm \\
8.65\end{array}$ & $\begin{array}{l}22.00 \pm \\
16.03^{*} \wedge\end{array}$ & - & - & 0.003 & $\begin{array}{c}11.78 \pm \\
8.75\end{array}$ & $\begin{array}{c}16.33 \pm \\
10.30 * \#\end{array}$ & - & - & 0.043 & - \\
\hline $\begin{array}{l}\text { Amenorrhoea } \\
\text { [months] }\end{array}$ & $\begin{array}{c}7.66 \pm \\
3.67\end{array}$ & $\begin{array}{c}11.29 \pm \\
4.08^{\wedge}\end{array}$ & - & - & 0.002 & $\begin{array}{c}7.69 \pm \\
6.12\end{array}$ & $\begin{array}{c}8.09 \pm \\
7.06\end{array}$ & - & - & 0.799 & - \\
\hline $\begin{array}{l}\text { Chemerin } \\
{[\mu \mathrm{g} / \mathrm{L}]}\end{array}$ & $\begin{array}{c}137.5 \pm \\
15.88^{*}\end{array}$ & $\begin{array}{c}119.26 \pm \\
20.02^{*}\end{array}$ & $<0.001$ & $<0.001$ & 0.056 & $\begin{array}{c}141.76 \\
\pm \\
17.16^{*}\end{array}$ & $\begin{array}{c}112.62 \\
\pm \\
16.84^{*}\end{array}$ & $<0.001$ & $<0.001$ & 0.059 & $\begin{array}{c}180.02 \\
\pm \\
17.73 \\
\end{array}$ \\
\hline $\mathrm{OC}[\mu \mathrm{mol} / \mathrm{L}]$ & $\begin{array}{l}3.52 \pm \\
0.65^{* \wedge}\end{array}$ & $\begin{array}{l}3.04 \pm \\
0.32 * \wedge \\
\end{array}$ & $<0.001$ & $<0.001$ & 0.010 & $\begin{array}{c}3.60 \pm \\
0.69 *\end{array}$ & $\begin{array}{l}3.18 \pm \\
0.53^{*} \#\end{array}$ & $<0.001$ & $<0.001$ & 0.008 & $\begin{array}{c}6.37 \pm \\
0.90\end{array}$ \\
\hline CTx [nmol/L] & $\begin{array}{c}6.06 \pm \\
1.17^{*}\end{array}$ & $\begin{array}{l}6.18 \pm \\
0.62 * \wedge\end{array}$ & $<0.001$ & $<0.001$ & 0.716 & $\begin{array}{c}6.03 \pm \\
1.18^{*}\end{array}$ & $\begin{array}{c}6.15 \pm \\
1.02^{*}\end{array}$ & $<0.001$ & $<0.001$ & 0.669 & $\begin{array}{c}8.94 \pm \\
1.33\end{array}$ \\
\hline $\begin{array}{l}\text { OPG } \\
\text { [pmol/L] }\end{array}$ & $\begin{array}{c}4.57 \pm \\
0.43^{*}\end{array}$ & $\begin{array}{c}4.67 \pm \\
0.56^{*}\end{array}$ & $<0.001$ & $<0.001$ & 0.462 & $\begin{array}{c}4.56 \pm \\
0.42^{*}\end{array}$ & $\begin{array}{c}4.58 \pm \\
0.46^{*}\end{array}$ & $<0.001$ & $<0.001$ & 0.846 & $\begin{array}{c}3.64 \pm \\
0.38\end{array}$ \\
\hline $\begin{array}{l}\text { sRANKL } \\
\text { [pmol/L] }\end{array}$ & $\begin{array}{c}0.70 \pm \\
0.08^{*}\end{array}$ & $\begin{array}{c}0.67 \pm \\
0.06^{*}\end{array}$ & $<0.001$ & $<0.001$ & 0.198 & $\begin{array}{c}0.68 \pm \\
0.12^{*}\end{array}$ & $\begin{array}{c}0.69 \pm \\
0.08^{*}\end{array}$ & $<0.001$ & $<0.001$ & 0.693 & $\begin{array}{c}0.54 \pm \\
0.07\end{array}$ \\
\hline $\begin{array}{l}\text { OPG/ } \\
\text { sRANKL }\end{array}$ & $\begin{array}{c}6.90 \pm \\
0.93^{*}\end{array}$ & $\begin{array}{c}6.00 \pm \\
0.91^{*}\end{array}$ & $<0.001$ & $<0.001$ & 0.002 & $\begin{array}{c}6.95 \pm \\
0.93^{*}\end{array}$ & $\begin{array}{l}6.01 \pm \\
0.81 * \#\end{array}$ & $<0.001$ & $<0.001$ & $<0.001$ & $\begin{array}{c}9.28 \pm \\
1.36\end{array}$ \\
\hline
\end{tabular}

Z-score — the number of SD from age-matched subjects; SD — standard deviation; SDS — standard deviation score; BMI — body mass index; OC — osteocalcin; CTx — C-terminal telopeptide of type I collagen $\alpha 1$ chain; OPG — osteoprotegerin; sRANKL — soluble receptor activator of nuclear factor- $\kappa \mathrm{B}$ ligand; ${ }^{*} \mathrm{p}<0.05$ vs. control group; $\wedge \mathrm{p}<0.05$ vs. normal s-BMD subgroup; $\# \mathrm{p}<0.05$ vs. normal TB-BMD subgroup 
control participants. Mean weight and BMI (expressed as absolute values and SDS), Cole index, OC, CTx, and the OPG/sRANKL ratio were significantly lower $(p<0.001)$ in the subgroups of girls with AN and normal and low s- and TB-BMD compared to the control group, while OPG and sRANKL were significantly higher ( $p<0.001)$. Mean weight expressed as absolute values and SDS ( $p=0.002$ and $p=0.001$, respectively), BMI-SDS ( $p=0.003)$, Cole index $(p<0.001)$, OC $(p=0.010)$, and the OPG/sRANKL ratio $(p=0.002)$ were markedly lower in the low s-BMD subgroup compared to the normal s-BMD subgroup, while the duration of the disease was significantly longer $(p=0.043)$. In the low TB-BMD subgroup the mean BMI-SDS $(p=0.002)$, Cole index $(p=0.001)$, OC $(p=0.008)$, and the OPG/sRANKL ratio $(p<0.001)$ were lower compared to the normal TB-BMD subgroup, while the duration of the disease was longer $(\mathrm{p}=0.043)$.

Table 2 shows correlations between the normal and low s- and TB-Z-score values, and clinical and anthropometric parameters, plasma levels of chemerin, and biochemical markers of bone turnover in the subgroup of girls with AN according to the DXA results. The normal s-Z-score values correlated significantly and positively with weight and BMI expressed as absolute values $(R=0.251, p=0.047$ and $R=0.261, p=0.039$, respectively), Cole index $(R=0.261, p=0.039)$, and the OPG/sRANKL ratio $(R=0.273, p=0.030)$, while low $\mathrm{s}$-Z-score values correlated significantly and positively only with the OPG/sRANKL ratio $(\mathrm{R}=0.780, \mathrm{p}=0.008)$. In turn, the normal TB-Z-score values correlated significantly and positively with weight and BMI expressed as absolute values and SDS $(R=0.296, p=0.043$ and $\mathrm{R}=0.347, \mathrm{p}=0.017$ as well as $\mathrm{R}=0.374, \mathrm{p}=0.010$ and $\mathrm{R}=0.351, \mathrm{p}=0.016$, respectively), Cole index $(\mathrm{R}=0.297, \mathrm{p}=0.043)$, and the OPG/sRANKL ratio $(\mathrm{R}=0.298, \mathrm{p}=0.042)$. Similar results were observed in the relationship with the low TB-Z-score values: significant correlation was observed with weight and BMI expressed as absolute values and SDS $(\mathrm{R}=0.437$, $\mathrm{p}=0.020$ and $\mathrm{R}=0.392, \mathrm{p}=0.039$ as well as $\mathrm{R}=0.451$, $\mathrm{p}=0.016$ and $\mathrm{R}=0.399, \mathrm{p}=0.035$, respectively), Cole index $(\mathrm{R}=0.402, \mathrm{p}=0.034)$, and the OPG/sRANKL ratio $(\mathrm{R}=0.398, \mathrm{p}=0.036)$. The duration of amenor-

Table 2. Correlation between values of bone mineral density of lumbar spine (s-BMD) and bone mineral density of total body (TB-BMD) expressed as Z-score and clinical and anthropometric parameters, plasma levels of chemerin, and biochemical markers of bone turnover in patients with anorexia nervosa $(A N)$ according to the DXA result

\begin{tabular}{|c|c|c|c|c|c|c|c|c|}
\hline \multirow{3}{*}{ Variables } & \multicolumn{4}{|c|}{ s-BMD } & \multicolumn{4}{|c|}{ TB-BMD } \\
\hline & \multicolumn{2}{|c|}{$\begin{array}{c}\text { Normal Z-score }>-2.0 \\
(n=63)(86.0 \%)\end{array}$} & \multicolumn{2}{|c|}{$\begin{array}{c}\text { Low Z-score } \leq-2.0 \\
(\mathrm{n}=12)(16.0 \%)\end{array}$} & \multicolumn{2}{|c|}{$\begin{array}{c}\text { Normal Z-score }>-2.0 \\
(n=47)(62.7 \%\end{array}$} & \multicolumn{2}{|c|}{$\begin{array}{c}\text { Low Z-score } \leq-2.0 \\
(\mathrm{n}=28)(37.3 \%)\end{array}$} \\
\hline & $\mathbf{R}$ & $\mathbf{p}$ & $\mathbf{R}$ & $\mathbf{p}$ & $\mathbf{R}$ & $\mathbf{p}$ & $\mathbf{R}$ & $\mathbf{p}$ \\
\hline Age [years] & -0.087 & 0.498 & -0.591 & 0.043 & -0.275 & 0.061 & -0.297 & 0.125 \\
\hline Heigh [m] & 0.170 & 0.183 & 0.252 & 0.429 & 0.260 & 0.078 & 0.257 & 0.187 \\
\hline Weight [kg] & $0.251^{*}$ & 0.047 & 0.394 & 0.205 & $0.296^{*}$ & 0.043 & $0.437^{*}$ & 0.020 \\
\hline Weight-SDS & 0.201 & 0.114 & 0.240 & 0.452 & $0.347^{*}$ & 0.017 & $0.392^{*}$ & 0.039 \\
\hline BMI $\left[\mathrm{kg} / \mathrm{m}^{2}\right]$ & $0.261^{*}$ & 0.039 & 0.406 & 0.190 & $0.374^{*}$ & 0.010 & $0.451^{*}$ & 0.016 \\
\hline BMI-SDS & 0.211 & 0.097 & 0.480 & 0.114 & $0.351^{*}$ & 0.016 & $0.399^{*}$ & 0.035 \\
\hline Cole's index (\%) & $0.270^{*}$ & 0.032 & 0.406 & 0.190 & $0.297^{*}$ & 0.043 & $0.402^{*}$ & 0.034 \\
\hline $\begin{array}{l}\text { Disease duration } \\
\text { [months] }\end{array}$ & -0.092 & 0.473 & -0.094 & 0.771 & -0.258 & 0.080 & -0.242 & 0.215 \\
\hline Amenorrhoea [months] & -0.232 & 0.067 & -0.288 & 0.364 & -0.183 & 0.218 & -0.222 & 0.256 \\
\hline $\begin{array}{l}\text { Amenorrhoea [months]/ } \\
\text { /disease duration } \\
\text { [months] }\end{array}$ & $0.514^{*}$ & $<0.001$ & 0.519 & 0.165 & $0.423^{*}$ & 0.003 & $0.681^{*}$ & $<0.001$ \\
\hline Chemerin [ng/mL] & 0.040 & 0.756 & 0.079 & 0.807 & 0.186 & 0.211 & $0.395^{*}$ & 0.038 \\
\hline OC $[\mu \mathrm{g} / \mathrm{L}]$ & 0.043 & 0.738 & 0.296 & 0.350 & 0.047 & 0.754 & 0.047 & 0.812 \\
\hline CTx [ng/L] & 0.225 & 0.076 & 0.278 & 0.382 & 0.009 & 0.952 & 0.054 & 0.785 \\
\hline OPG [ng/L] & -0.242 & 0.056 & -0.474 & 0.120 & -0.220 & 0.137 & -0.015 & 0.940 \\
\hline sRANKL [ng/L] & -0.163 & 0.202 & -0.066 & 0.838 & -0.045 & 0.764 & -0.103 & 0.602 \\
\hline OPG/sRANKL & $0.273^{*}$ & 0.030 & $0.780^{*}$ & 0.008 & $0.298^{*}$ & 0.042 & $0.398^{*}$ & 0.036 \\
\hline
\end{tabular}

Z-score — the number of SD from age-matched subjects; SD — standard deviation; SDS — standard deviation score; BMI — body mass index; OC — osteocalcin; CTx — C-terminal telopeptide of type I collagen $\alpha 1$ chain; OPG — osteoprotegerin; sRANKL — soluble receptor activator of nuclear factor- $\kappa \mathrm{B}$ ligand; ${ }^{*} p<0.05$ - statistically significant correlation coefficients 
Table 3. Correlation between plasma chemerin, clinical and anthropometric parameters, and biochemical markers of bone turnover in subgroups of girls with anorexia nervosa $(A N)$ and normal (Z-score $>-2.0)$ and low (Z-score $\leq-2.0)$ bone mineral density of lumbar spine (s-BMD) and bone mineral density of total body (TB-BMD)

\begin{tabular}{|c|c|c|c|c|c|c|c|c|}
\hline \multirow{3}{*}{ Variables } & \multicolumn{4}{|c|}{ s-BMD } & \multicolumn{4}{|c|}{ TB-BMD } \\
\hline & \multicolumn{2}{|c|}{$\begin{array}{c}\text { Normal Z-score }>-2.0 \\
(n=63)(84.0 \%)\end{array}$} & \multicolumn{2}{|c|}{$\begin{array}{c}\text { Low Z-score } \leq-2.0 \\
(\mathrm{n}=12)(16.0 \%)\end{array}$} & \multicolumn{2}{|c|}{$\begin{array}{c}\text { Normal Z-score }>-2.0 \\
(n=47)(62.7 \%)\end{array}$} & \multicolumn{2}{|c|}{$\begin{array}{c}\text { Low Z-score } \leq-2.0 \\
(\mathrm{n}=28)(37.3 \%)\end{array}$} \\
\hline & $\mathbf{R}$ & $\mathbf{p}$ & $\mathbf{R}$ & $\mathbf{p}$ & $\mathbf{R}$ & p & $\mathbf{R}$ & p \\
\hline Age [years] & -0.056 & 0.663 & 0.467 & 0.126 & -0.136 & 0.362 & $-0.489 *$ & 0.008 \\
\hline Heigh [m] & -0.174 & 0.173 & 0.466 & 0.127 & -0.255 & 0.084 & 0.340 & 0.077 \\
\hline Weight [kg] & 0.022 & 0.864 & $0.717^{*}$ & 0.009 & 0.123 & 0.410 & $0.488^{*}$ & 0.008 \\
\hline Weight-SDS & 0.159 & 0.213 & $0.710^{*}$ & 0.010 & 0.059 & 0.694 & 0.256 & 0.189 \\
\hline BMI [kg/m²] & 0.120 & 0.349 & $0.850^{*}$ & 0.001 & 0.016 & 0.915 & $0.498^{*}$ & 0.007 \\
\hline BMI-SDS & 0.183 & 0.151 & $0.817^{*}$ & $<0.001$ & 0.125 & 0.402 & 0.318 & 0.099 \\
\hline Cole index (\%) & 0.128 & 0.317 & $0.849 *$ & 0.001 & 0.041 & 0.784 & $0.397^{*}$ & 0.036 \\
\hline Disease duration [months] & 0.239 & 0.059 & 0.143 & 0.657 & 0.175 & 0.239 & $0.395^{*}$ & 0.038 \\
\hline Amenorrhoea [months] & 0.100 & 0.436 & 0.029 & 0.929 & 0.079 & 0.598 & 0.083 & 0.675 \\
\hline $\mathrm{OC}[\mu \mathrm{mol} / \mathrm{L}]$ & 0.119 & 0.353 & -0.218 & 0.496 & 0.136 & 0.362 & 0.061 & 0.758 \\
\hline CTx [nmol/L] & 0.076 & 0.554 & 0.450 & 0.142 & 0.079 & 0.598 & 0.154 & 0.434 \\
\hline OPG [pmol/L] & 0.022 & 0.864 & -0.217 & 0.498 & -0.178 & 0.231 & -0.029 & 0.883 \\
\hline sRANKL [pmol/L] & 0.074 & 0.564 & -0.183 & 0.569 & -0.220 & 0.137 & 0.110 & 0.577 \\
\hline OPG/sRANKL & 0.087 & 0.498 & $0.713^{*}$ & 0.009 & 0.032 & 0.831 & $0.399 *$ & 0.035 \\
\hline
\end{tabular}

Z-score — number the of SD from age-matched subjects; SD — standard deviation; BMI — body mass index; SDS — standard deviation score; OC — osteocalcin;

CTx — C-terminal telopeptide of type I collagen $\alpha 1$ chain; OPG — osteoprotegerin; sRANKL — soluble receptor activator of nuclear factor- $\kappa \mathrm{B}$ ligand;

${ }^{*} \mathrm{p}<0.05$ - statistically significant correlation coefficients

rhoea was statistically different between normal and low BMD groups along with duration of illness (sBMD subgroups: $\mathrm{R}=0.514, \mathrm{p}<0.001$ and $\mathrm{R}=0.519$, $\mathrm{p}=0.165$; TB-BMD subgroups: $\mathrm{R}=0.423, \mathrm{p}=0.003$ and $0.681, \mathrm{p}<0.001$, respectively). Although values of correlation coefficients for the relationship between the normal and low s-BMD subgroups were similar, the relationship between them was significant due to the low number of patients in the low s-BMD subgroup $(\mathrm{n}=12)$ compared to the normal s-BMD subgroup $(\mathrm{n}=63)$. The low TB-BMD subgroup was the only one in which low TB-BMD values correlated significantly and positively with chemerin $(\mathrm{R}=0.395, \mathrm{p}=0.036)$.

Table 3 presents correlations between plasma levels of chemerin and clinical and anthropometric parameters as well as plasma levels of biochemical markers of bone turnover in subgroups of patients with AN according to DXA results. No significant correlations were observed between chemerin, clinical, and anthropometric parameters and biochemical markers of bone turnover in the normal s- and TB-BMD subgroups. In the low s-BMD subgroup chemerin levels correlated significantly and positively with weight and BMI expressed as absolute values and SDS $(\mathrm{R}=0.717$, $\mathrm{p}=0.009$ and $\mathrm{R}=0.710, \mathrm{p}=0.010$ as well as $\mathrm{R}=0.850$, $\mathrm{p}=0.001$ and $\mathrm{R}=0.817, \mathrm{p}<0.001$, respectively), Cole index $(\mathrm{R}=0.849$, $\mathrm{p}=0.001)$, and the OPG/sRANKL ratio $(R=0.713, p=0.009)$. In the low TB-BMD subgroup chemerin levels correlated significantly and positively with weight and BMI expressed as absolute values $(\mathrm{R}=0.488, \mathrm{p}=0.008$ and $\mathrm{R}=0.498, \mathrm{p}=0.007$, respectively), Cole index $(R=0.397, p=0.036)$, the duration of the disease $(R=0.395, p=0.038)$, and the OPG/sRANKL ratio $(\mathrm{R}=0.399, \mathrm{p}=0.035)$, while its correlation with age was significant and negative $(\mathrm{R}=-0.489, \mathrm{p}=0.008)$.

\section{Discussion}

As compared with normal-weight adolescents, girls with AN have lower levels of bone formation and resorption markers [4, 7, 8, 10, 16, 18, 19, 21-24, 52], suggestive of overall decreased bone accrual and a low remodelling state. In the present study, significant suppression of bone metabolism markers (OC, CTx) was associated with alterations in the levels of OPG, sRANKL, and/or the OPG/sRANKL ratio. Similarly to our previous investigations [18, 19, 22-24, 26, 27], the mean plasma sRANKL and OPG levels were significantly higher in patients with AN while the OPG/sRANKL ratio was markedly lower compared to healthy participants. These changes might, in turn, impair the mechanism compensating for bone remodelling disturbances and, in consequence, lead to loss of bone mass. 
Studies of bone status in adolescents with AN demonstrated low BMD in about $6-32 \%$ of the patients [ $4-6$, 28-30]. The authors $[5,6,9,28-31,33,34,52-54]$ are consistent that AN affects both trabecular and cortical bone compartments. However, some authors suggest that adolescent females with AN exhibit preferential loss of trabecular bone, which is more metabolically active and has a higher turnover rate. They conclude that the lumbar spine, which has a greater proportion of trabecular bone, tends to be more affected than the hip or total body. Conversely, other investigators suggest that cortical bone is more severely affected in adolescent girls with AN than trabecular bone [55, 56]. Oświęcimska et al. [57] concluded that cortical bone is more sensitive to undernutrition during puberty than trabecular bone. The presented results demonstrate also that changes ( $\mathrm{D}$ - between baseline and $19.4 \pm 5.6$ months of follow-up) in s- and TB-BMD correlated significantly and positively with changes in weight, height, and bone specific alkaline phosphatase.

In the present study in girls with $\mathrm{AN}$, the mean $\mathrm{BMD}$ Z-score for lumbar spine was higher than for TB $(-0.82$ and -1.63 , respectively). Baseline low s- and TB-BMD Zscores were observed in 12/75 (16.0\%) and 28/75 (37.3\%) of the patients, respectively. Similar results were observed in our earlier research [34]. Moreover, nutritional indices, OC, and the OPG/sRANKL ratio were lower while the duration of the disease was longer in low sand TB-BMD. The Z-score values in the low TB-BMD subgroup and normal s- and TB-BMD subgroups correlated significantly and positively with nutritional indices. Major differences between examined variables and more pronounced correlations were generally observed in low BMD than in the normal BMD subgroups, and in TB-BMD than in s-BMD subgroups. However, in the low BMD subgroups these dependencies were not always significant due to the low number of patients (especially in the low s-BMD subgroup). The obtained results confirm previous observations $[18,19,21-24,52$, 57] that undernutrition-related deficit of adipose tissue may result in inadequate values of biochemical markers of bone turnover (especially OC) in AN patients and indicates that the OPG/RANKL ratio is an important determinant of these alteration. Consequently, it may contribute to loss of bone mass. It should also be emphasized that the presented results confirm our earlier observation [34] that BMD differs depending on the examined skeletal area in adolescent girls with AN. Cortical bone is more severely affected than trabecular bone. It is consistent with other reports, which indicated that AN onset at a younger age mostly affects the development or maintenance of cortical bone [31, 33]. Other authors $[58,59]$ also observed that in girls with AN, cortical bone was more often affected. Seeman et al. [60] observed that patients with prepubertal onset of AN had bone deficits in vertebral and femoral areas whereas patients with adult onset showed bone loss mostly in vertebral areas. Therefore, AN affects different regions at different ages depending on the stage of bone growth and development; before puberty appendicular growth is more rapid than axial, whereas during puberty appendicular growth slows and axial growth accelerates.

Several human studies, including especially studies in adolescents with $\mathrm{AN}$, have suggested that a majority of adipokines [14-18, 23, 24, 27,36-38,40-46], and maybe also chemerin $[16,36,38,40,42,44]$, have a relationship with osteoporosis and BMD. In vitro data provide evidence that chemerin is negatively associated with bone metabolism; knockdown of the chemerin gene in bone stromal cells resulted in an increase in osteoblast marker gene expression and mineralization [36]. Neutralization of chemerin resulted in a near-complete loss of osteoclastogenesis, shown by reduced osteoclast marker gene expression, and resorption [38]. The relationship between chemerin and BMD or broadband ultrasound attenuation (BUA) was also studied in humans [40-46], but the results are not always unequivocal. In a study by He et al. [40], patients with osteoporosis had higher serum levels of chemerin compared to healthy controls. Furthermore, chemerin had a negative effect on femoral and lumbar spine BMD assessed by DXA in patients with osteoporosis and healthy controls. However, after adjustment for age and BMI, the correlation between osteoporosis and chemerin disappeared. Shi et al. [44] reported an inverse association between chemerin and s-BMD in obese women with postmenopausal osteoporosis. However, contrary to the study by He et al. [40], the correlation between serum chemerin and bone-related parameters remained significant even after adjustment for age, BMI, and fat mass parameters [44]. Terzoudis et al. [45] observed that chemerin levels were increased in patients with bowel disease compared to healthy participants, and they were positively associated with the development of osteoporosis. Li et al. [46] showed that chemerin levels were increased while BMD was decreased in patients with newly diagnosed Graves' disease (GD) compared with the control group. Furthermore, chemerin was positively correlated with CTx and negatively with fat mass and fat mass index. A negative correlation was also revealed between chemerin and BMD. After adjusting for age, fat mass, or BMI, the correlation of chemerin with BMD remained significant, which indicates that the decrease of BMD in patients with GD is not only related to the direct or indirect effect of excessive thyroid hormones but also to the negative regulation of bone metabolism due to the elevated chemerin level. Other authors [42] 
presented an inverse association between chemerin and bone quality assessed by BUA in peri/premenopausal women. The authors suggest that high chemerin levels may minimize the peak bone mass and thereby promote age-related bone loss. Kadric et al. [41] revealed an inverse association between chemerin levels and bone quality assessed by BUA in adults from the general population. This association, only seen in obese participants, was dependent on the subjects' BMI, and might have been due to a chemerin-induced negative effect on bone metabolism. Contrary to above-mentioned authors, Engin-Ustum et al. [43] showed that chemerin levels were decreased in patients with osteoporosis compared to the control participants. Although these data were partly conflicting, they generally indicated that, along with other adipokines [14-18, 23, 24, 27], chemerin may also act as a regulator of bone mass [36-46].

Only a few studies have investigated serum chemerin levels in patients with $\mathrm{AN}$, the disease being recognized as a good biological model of chronic adipose tissue atrophy and a disorder of energy metabolism. Plasma chemerin levels present opposite changes in children and adolescents with obesity and anorexia nervosa, suggesting that chemerin is a good marker of nutritional status [47]. Our previous study [48] demonstrated a decrease in serum chemerin levels in adolescent girls with AN compared to age-matched healthy and obese subjects. However, after adjusting for BMI, serum chemerin levels in the AN group were significantly lower than those of healthy controls but statistically higher than in the obese group. Significant positive correlations were observed between serum chemerin and body weight, BMI, and Cole's index in all examined participants, while no such correlations were revealed in individual groups. A significant positive relationship between serum chemerin and insulin levels was also found in all examined subjects. These findings indicate that chemerin is strongly associated with nutritional status in adolescent girls with AN. After adjustment for BMI, lower chemerin levels may result from the loss of body weight caused by nutrition restrictions and/or intensive physical effort in $\mathrm{AN}$ and compensatory mechanisms preventing further adipose tissue expansion, metabolic dysfunction, and insulin resistance in obesity [48].

To the best of our knowledge, there are no reports on the relationship between chemerin and skeletal status in girls with AN; therefore, we carried out a comparative analysis between chemerin, clinical and anthropometric parameters, as well as biochemical markers of bone turnover in girls with $\mathrm{AN}$ and normal s- and TB-BMD Z-score with those in girls with AN and low s- and TB-BMD Z-score values. The present study confirms earlier observations [48] that the mean chemerin level was lower in girls with AN compared to that in the control group. The obtained results also confirm the previously formulated hypothesis that undernutrition may affect chemerin production in patients with AN [48]. Our results have also shown that chemerin acts as a coordinator of the dynamic balance between bone formation and resorption processes. Moreover, desynchronization between bone remodelling and the RANKL/RANK/OPG system was observed, which can lead to changes in bone mass during adolescence. Higher values of correlation coefficients between the above-mentioned relationships were generally observed in subgroups of patients with low BMD, compared to those with normal BMD. Furthermore, cortical bone sites were more severely responsive to chemerin than sites of trabecular bone. Therefore, we concluded that the effect of chemerin on skeletal status depends not only on the degree of undernutrition and adipose tissue deficit but also on the sensitivity of the DXA-scanned area to this adipokine.

Certain differences in the obtained results regarding the relationship between chemerin and skeletal status in humans (children, adolescents, and adult subjects suffering from AN) might be associated with some interference from endogenous factors the levels of which are severely altered in patients with AN (including oestrogens, glucocorticoids, parathyroid hormone, thyroid hormones, vitamin $\mathrm{D}$, adipokines other than chemerin, as well as cytokines) [2-6, 11-14, 16, 18-20, 23, 24, 27, $61-71]$. Some of these can modulate chemerin production or are modulated by chemerin [15-20, 61-71]. They may also have a direct or RANKL/RANK/OPG system-mediated effect on the balance between bone formation and resorption processes. An indirect influence of chemerin on bone metabolism should be taken into consideration, e.g. via its effect on the secretion of several osteotropic factors including proinflammatory cytokines, such as IL-1, IL-6, TNF- $\alpha$, IL-11, IL-15 [19, 20, 68-65, 70], or adipokines [15-17, 61, 67, 69, 71].

The limitations of our study must be mentioned. First, due to the absence of a control group, we could not compare the BMD of the AN group with that of healthy participants. It is because parents or caregivers of the control group did not agree for a DXA examination. Second, the low number of participants in the low s-BMD subgroup hindered some of the statistical analysis. However, because the impact of chemerin on bone health of adolescent girls suffering from AN has not been explored previously, we believe that our study will serve as a basis for future investigation in this field. Confirmation by other population-based studies is necessary to prove the accuracy and the strength of our results. 


\section{Conclusions}

Undernutrition may result in inadequate chemerin production and skeletal disorders in girls with AN.

Chemerin acts as a coordinator of the dynamic balance between bone remodelling and the OPG/RANKL ratio in adolescent girls with $\mathrm{AN}$; consequently, it may contribute to bone mass loss.

Cortical bone sites seem to be more severely responsive to chemerin actions than trabecular bone sites.

\section{Conflict of interest}

None declared.

\section{References}

1. Keski-Rahkonen A, Mustelin L. Epidemiology of eating disorders in Europe: prevalence, incidence, comorbidity, course, consequences, and risk factors. Curr Opin Psychiatry. 2016; 29(6): 340-345 doi: 10.1097/YCO.0000000000000278, indexed in Pubmed: 27662598.

2. Rosen CJ, Klibanski A. Bone, fat, and body composition: evolv ing concepts in the pathogenesis of osteoporosis. Am J Med. 2009; 122(5): 409-414, doi: 10.1016/j.amjmed.2008.11.027, indexed in Pubmed: 19375545.

3. Misra M, Klibanski A. Anorexia nervosa and osteoporosis. Rev Endocr Metab Disord. 2006; 7(1-2): 91-99, doi: 10.1007/s11154-006-9005-1, indexed in Pubmed: 16972186.

4. Misra M, Klibanski A. Anorexia nervosa and bone. J Endocrinol. 2014; 221(3): R163-R176, doi: 10.1530/JOE-14-0039, indexed in Pubmed: 24898127.

5. Faje AT, Fazeli PK, Miller KK, et al. Fracture risk and areal bone mineral density in adolescent females with anorexia nervosa. Int J Eat Disord. 2014; 47(5): 458-466, doi: 10.1002/eat.22248, indexed in Pubmed: 24430890.

6. Misra M, Golden NH, Katzman DK. State of the art systematic review of bone disease in anorexia nervosa. Int J Eat Disord. 2016; 49(3): 276-292, doi: 10.1002/eat.22451, indexed in Pubmed: 26311400.

7. Fazeli PK, Klibanski A. Bone metabolism in anorexia nervosa. Cur Osteoporos Rep. 2014; 12(1): 82-89, doi: 10.1007/s11914-013-0186-8, indexed in Pubmed: 24419863.

8. Fazeli PK, Klibanski A. Effects of Anorexia Nervosa on Bone Metabolism. Endocr Rev. 2018; 39(6): 895-910, doi: 10.1210/er.2018-00063, indexed in Pubmed: 30165608.

9. Fazeli PK. Low bone mineral density in anorexia nervosa: Treatments and challenges. Clin Rev Bone Miner Metab. 2019; 17(2): 65-76, doi: 10.1007/s12018-019-09260-4, indexed in Pubmed: 31938025.

10. Misra M, Klibanski A. The neuroendocrine basis of anorexia nervosa and its impact on bone metabolism. Neuroendocrinology. 2011; 93(2): 65-73, doi: 10.1159/000323771, indexed in Pubmed: 21228564.

11. Misra M, Klibanski A. Endocrine consequences of anorexia nervosa. Lance Diab Endocrinol. 2014; 2(7): 581-592, doi: 10.1016/s2213-8587(13)70180-3, indexed in Pubmed: 24731664.

12. Baskaran C, Misra M, Klibanski A. Effects of anorexia nervosa on the endocrine system. Pediatr Endocrinol Rev . 2017; 14(3): 302-311, doi: 10.17458/per.vol14.2017, indexed in Pubmed: 28508601.

13. Milos G, Hebebrand J. [Endocrine Consequences of Anorexia Nervosa] Praxis (Bern 1994). 2019; 108(14): 899-904, doi: 10.1024/1661-8157/a003348, indexed in Pubmed: 31662110.

14. Misra M, Miller KK, Cord J, et al. Relationships between serum adipokines, insulin levels, and bone density in girls with anorexia nervosa. J Clin Endocrinol Metab. 2007; 92(6): 2046-2052, doi: 10.1210/jc.2006-2855, indexed in Pubmed: 17356044

15. Biver E, Salliot C, Combescure C, et al. Influence of adipokines and ghrelin on bone mineral density and fracture risk: a systematic review and meta-analysis. J Clin Endocrinol Metab. 2011; 96(9): 2703-2713, doi: 10.1210/jc.2011-0047, indexed in Pubmed: 21778223.

16. Liu Y, Song CY, Wu SS, et al. Novel adipokines and bone metabolism Int J Endocrinol. 2013; 2013: 895045, doi: 10.1155/2013/895045, indexed in Pubmed: 23431296.

17. Blüher M, Mantzoros CS. From leptin to other adipokines in health and disease: facts and expectations at the beginning of the 21st century. Metabolism. 2015; 64(1): 131-145, doi: 10.1016/j.metabol.2014.10.016, indexed in Pubmed: 25497344.

18. Ostrowska Z,Ziora K, Oświęcimska J, et al. Bone metabolism, osteoprotegerin, receptor activator of nuclear factor- $\kappa \mathrm{B}$ ligand and selected adipose tissue hormones in girls with anorexia nervosa. Endokrynol Pol. 2014; 65(1): 33-39, doi: 10.5603/EP.2014.0005, indexed in Pubmed: 24549600.

19. Ostrowska Z, Ziora K, Oświeccimska J, et al. Selected pro-inflammatory cytokines, bone metabolism, osteoprotegerin, and receptor activator of nuclear factor-kB ligand in girls with anorexia nervosa. Endokrynol Pol. 2015; 66(4): 313-321, doi: 10.5603/EP.2015.0040, indexed in Pubmed: 26323468.

20. Solmi M, Veronese N, Favaro A, et al. Inflammatory cytokines and anorexia nervosa: A meta-analysis of cross-sectional and longitudina studies. Psychoneuroendocrinology. 2015; 51: 237-252, doi: 10.1016/j. psyneuen.2014.09.031, indexed in Pubmed: 25462897.

21. Soyka LA, Grinspoon S, Levitsky LL, et al. The effects of anorexia nervosa on bone metabolism in female adolescents. J Clin Endocrino Metab. 1999; 84(12): 4489-4496, doi: 10.1210/jcem.84.12.6207, indexed in Pubmed: 10599707

22. Ostrowska Z, Ziora K, Oświęcimska J, et al. RANKL/RANK/OPG system and bone status in females with anorexia nervosa. Bone. 2012; 50(1): 156-160, doi: 10.1016/j.bone.2011.09.054, indexed in Pubmed: 22001124.

23. Ostrowska Z, Ziora K, Oświęcimska J, et al. Vaspin and selected indices of bone status in girls with anorexia nervosa. Endokrynol Pol. 2016, 67(6): 599-606, doi: 10.5603/EP.2016.0070, indexed in Pubmed: 28042653

24. Gołąbek K, Ostrowska Z, Ziora K, et al. Association between omentin-1, bone metabolism markers, and cytokines of the RANKL/RANK/OPG system in girls with anorexia nervosa. Endokrynol Pol. 2015; 66(6): 514-520, doi: 10.5603/EP.2015.0063, indexed in Pubmed: 26662650.

25. Infante M, Fabi A, Cognetti F, et al. RANKL/RANK/OPG system beyond bone remodeling: involvement in breast cancer and clinical perspectives. J Exp Clin Cancer Res. 2019; 38(1): 12, doi: 10.1186/s13046-018-1001-2, indexed in Pubmed: 30621730

26. Misra M, Soyka LA, Miller KK, et al. Serum osteoprotegerin in adolescent girls with anorexia nervosa. J Clin Endocrinol Metab. 2003; 88(8): 3816-3822, doi: 10.1210/jc.2003-030088, indexed in Pubmed: 12915674.

27. Muñoz-Calvo MT, Barrios V, García de Alvaro MT, et al Maintained malnutrition produces a progressive decrease in (OPG)/RANKL ratio and leptin levels in patients with anorexia nervosa. Scand J Clin Lab Invest. 2007; 67(4): 387-393, doi: 10.1080/00365510601110130, indexed in Pubmed: 17558893.

28. Crabtree NJ, Arabi A, Bachrach LK, et al. International Society for Clinical Densitometry. Dual-energy X-ray absorptiometry interpretation and reporting in children and adolescents: the revised 2013 ISCD Pediatric Official Positions. J Clin Densitom. 2014; 17(2): 225-242, doi: 10.1016/j. jocd.2014.01.003, indexed in Pubmed: 24690232

29. Estrada A, Ramnitz MS, Gafni RI. Bone densitometry in children and adolescents. Curr Opin Obstet Gynecol. 2014; 26(5): 339-346, doi: 10.1097/GCO.0000000000000100, indexed in Pubmed: 25144595.

30. Rauch F Schoenau E. Changes in bone density during childhood and adolescence: an approach based on bone's biological organization. J Bone Miner Res. 2001; 16(4): 597-604, doi: 10.1359/jbmr.2001.16.4.597, indexed in Pubmed: 11315987.

31. Milos G, Spindler A, Rüegsegger P, et al. Cortical and trabecular bone density and structure in anorexia nervosa. Osteoporos Int. 2005; 16(7): 783-790, doi: 10.1007/s00198-004-1759-2, indexed in Pubmed: 15452690

32. Agarwal S, Rosete $\mathrm{F}$, Zhang $\mathrm{C}$, et al. In vivo assessment of trabecular and cortical bone microstructure. Clin Calcium. 2011; 21(7): 1011-1019, doi: CliCa110710111019, indexed in Pubmed: 21719981.

33. Faje AT, Karim L, Taylor A, et al. Adolescent girls with anorexia nervosa have impaired cortical and trabecular microarchitecture and lower estimated bone strength at the distal radius. J Clin Endocrinol Metab. 2013; 98(5): 1923-1929, doi: 10.1210/jc.2012-4153, indexed in Pubmed: 23509107.

34. Morawiecka-Pietrzak M, Malczyk Ż, Dąbrowska E, et al. Endokrynol Pol. 2021; 72(4): 336-346, doi: 10.5603/EP.a2021.0036, indexed in Pubmed: 34010435

35. de Paula FJ, Rosen CJ. Structure and Function of Bone Marrow Adipocytes. Compr Physiol. 2017; 8(1): 315-349, doi: 10.1002/cphy.c170010, indexed in Pubmed: 29357131.

36. Muruganandan S, Roman AA, Sinal CJ. Role of chemerin/CMKLR1 signaling in adipogenesis and osteoblastogenesis of bone marrow stem cells. J Bone Miner Res. 2010; 25(2): 222-234, doi: 10.1359/jbmr.091106, indexed in Pubmed: 19929432

37. Goralski KB, McCarthy TC, Hanniman EA, et al. Chemerin, a novel adipokine that regulates adipogenesis and adipocyte metabolism. J Bio Chem. 2007; 282(38): 28175-28188, doi: 10.1074/jbc.M700793200, indexed in Pubmed: 17635925.

38. Muruganandan S, Dranse HJ, Rourke JL, et al. Chemerin neutralization blocks hematopoietic stem cell osteoclastogenesis. Stem Cells. 2013 31(10): 2172-2182, doi: 10.1002/stem.1450, indexed in Pubmed: 23766088.

39. Muruganandan S, Sinal CJ. The impact of bone marrow adipocytes on osteoblast and osteoclast differentiation. IUBMB Life. 2014; 66(3): 147-155, doi: 10.1002/iub.1254, indexed in Pubmed: 24638917.

40. He J, Li JC, Xie H, et al. Serum Chemerin Levels in relation to Osteoporosis and Bone Mineral Density: A Case-Control Study. Dis Markers. 2015; 2015: 786708, doi: 10.1155/2015/786708, indexed in Pubmed: 26170530. 
41. Kadric L, Zylla S, Nauck M, et al. Associations Between Plasma Chemerin Concentrations and Bone Quality in Adults From the General Population. Endocrinology. 2018; 159(6): 2378-2385, doi: 10.1210/en.2018-00157, indexed in Pubmed: 29701774

42. Menzel J, Biemann R, Aleksandrova K, et al. The cross-sectional association between chemerin and bone health in peri/pre and postmenopausal women: results from the EPIC-Potsdam study. Menopause. 2018; 25(5): 574-578, doi: 10.1097/GME.0000000000001041, indexed in Pubmed: 29206770.

43. Engin-Üstün Y, Çağlayan EK, Göçmen AY, et al. Postmenopausal Osteoporosis Is Associated with Serum Chemerin and Irisin but Not with Apolipoprotein M Levels. J Menopausal Med. 2016; 22(2): 76-79, doi: 10.6118/jmm.2016.22.2.76, indexed in Pubmed: 27617241.

44. Shi L, Mao C, Wang X, et al. Association of chemerin levels and bone mineral density in Chinese obese postmenopausal women. Medicine (Baltimore). 2016; 95(35): e4583, doi: 10.1097/MD.0000000000004583, indexed in Pubmed: 27583869.

45. Terzoudis S, Malliaraki N, Damilakis J, et al. Chemerin, visfatin, and vaspin serum levels in relation to bone mineral density in patients with inflammatory bowel disease. Eur J Gastroenterol Hepatol. 2016; 28(7): 814-819, doi: 10.1097/MEG.0000000000000617, indexed in Pubmed: 26934527.

46. Li Y, Chang J, Jiang T. [Serum level of chemerin and bone mineral density in patients with Graves' disease]. Zhong Nan Da Xue Xue Bao Yi Xue Ban. 2017; 42(8): 947-952, doi: 10.11817/j.issn.1672-7347.2017.08.02, indexed in Pubmed: 28872087.

47. Leoni MC, Pizzo D, Marchi A. [Adipocytokines: potential biomarkers for childhood obesity and anorexia nervosa]. Minerva Pediatr. 2010; 62(2): 171-178, indexed in Pubmed: 20440237.

48. Oświecimska JM, Ziora KT, Suwała A, et al. Chemerin serum levels in girls with anorexia nervosa. Neuro Endocrinol Lett. 2014; 35(6): 490-496, indexed in Pubmed: 25433840.

49. Gordon CM, Leonard MB, Zemel BS, et al. International Society for Clinical Densitometry. 2013 Pediatric Position Development Conference: executive summary and reflections. J Clin Densitom. 2014; 17(2): 219-224, doi: 10.1016/j.jocd.2014.01.007, indexed in Pubmed: 24657108.

50. Bachrach LK, Gordon CM. SECTION ON ENDOCRINOLOGY. Bone Densitometry in Children and Adolescents. Pediatrics. 2016; 138(4), doi: 10.1542/peds.2016-2398, indexed in Pubmed: 27669735.

51. Palczewska I, Niedźwiedzka Z. [Somatic development indices in children and youth of Warsaw]. Med Wieku Rozw 2001. 2001; 5(2_Suppl.1): 18-118, indexed in Pubmed: 11675534.

52. Oświęcimska J, Ziora K, Pluskiewicz W, et al. Ocena gęstości mineralnej kości oraz markerów metabolizmu kostnego u dziewcząt $\mathrm{z}$ jadłowstrętem psychicznym. Doniesienie wstępne. Endokrynol Pediatr. 2004; 3(2): 21-32.

53. American Psychiatric Association. Diagnostic and Statistical Manual of Mental Disorders (DSM-V). American Psychiatric Association, Washington 2013.

54. Morawiecka-Pietrzak M, Ziora K, Ostrowska Z. Interpretation of bone densitometry and definition of osteoporosis in children and adolescents. Pediatr Pol. 2019; 94(4): 241-247, doi: 10.5114/polp.2019.88041.

55. Herzog W, Deter HC, Fiehn W, et al. Medical findings and predictors of long-term physical outcome in anorexia nervosa: a prospective, 12-year follow-up study. Psychol Med. 1997; 27(2): 269-279, doi: 10.1017/s0033291796004394, indexed in Pubmed: 9089820.

56. Brooks ER, Ogden BW, Cavalier DS. Compromised bone density 11.4 years after diagnosis of anorexia nervosa. J Womens Health. 1998; 7(5): 567-574, doi: 10.1089/jwh.1998.7.567, indexed in Pubmed: 9650157.
57. Oświecimska J, Ziora K, Pluskiewicz W, et al. Skeletal status and laboratory investigations in adolescent girls with anorexia nervosa. Bone. 2007; 41(1): 103-110, doi: 10.1016/j.bone.2007.03.018, indexed in Pubmed: 17493887.

58. Maïmoun L, Guillaume S, Lefebvre P, et al. Role of sclerostin and dickkopf- 1 in the dramatic alteration in bone mass acquisition in adolescents and young women with recent anorexia nervosa. J Clin Endocrinol Metab. 2014; 99(4): E582-E590, doi: 10.1210/jc.2013-2565, indexed in Pubmed: 24471564.

59. Kandemir N, Slattery M, Ackerman KE, et al. Bone Parameters in Anorexia Nervosa and Athletic Amenorrhea: Comparison of Two Hypothalamic Amenorrhea States. J Clin Endocrinol Metab. 2018; 103(6): 2392-2402, doi: 10.1210/jc.2018-00338, indexed in Pubmed: 29659886.

60. Seeman E, Karlsson MK, Duan Y. On exposure to anorexia nervosa, the temporal variation in axial and appendicular skeletal development predisposes to site-specific deficits in bone size and density: a cross-sectional study. J Bone Miner Res. 2000; 15(11): 2259-2265, doi: 10.1359/jbmr.2000.15.11.2259, indexed in Pubmed: 11092408.

61. Legroux-Gérot I, Vignau J, D’Herbomez M, et al. Evaluation of bone loss and its mechanisms in anorexia nervosa. Calcif Tissue Int. 2007; 81(3): 174-182, doi: 10.1007/s00223-007-9038-9, indexed in Pubmed: 17668143.

62. Galusca B, Bossu C, Germain N, et al. Age-related differences in hormonal and nutritional impact on lean anorexia nervosa bone turnover uncoupling. Osteoporos Int. 2006; 17(6): 888-896, doi: 10.1007/s00198-005-0063-0, indexed in Pubmed: 16541206.

63. Ernst MC, Sinal CJ. Chemerin: at the crossroads of inflammation and obesity. Trends Endocrinol Metab. 2010; 21(11): 660-667, doi: 10.1016/j. tem.2010.08.001, indexed in Pubmed: 20817486.

64. Weigert J, Neumeier M, Wanninger J, et al. Systemic chemerin is related to inflammation rather than obesity in type 2 diabetes. Clin Endocrinol (Oxf). 2010; 72(3): 342-348, doi: 10.1111/j.1365-2265.2009.03664.x, indexed in Pubmed: 19558533.

65. Lehrke M, Becker A, Greif M, et al. Chemerin is associated with markers of inflammation and components of the metabolic syndrome but does not predict coronary atherosclerosis. Eur J Endocrinol. 2009; 161(2): 339-344, doi: 10.1530/EJE-09-0380, indexed in Pubmed: 19497986.

66. Parlee SD, Ernst MC, Muruganandan S, et al. Serum chemerin levels vary with time of day and are modified by obesity and tumor necrosis factor-\{alpha\}. Endocrinology. 2010; 151(6): 2590-2602, doi: 10.1210/en.2009-0794, indexed in Pubmed: 20363880.

67. Yu S, Zhang Y, Li MZ, et al. Chemerin and apelin are positively correlated with inflammation in obese type 2 diabetic patients. Chin Med J (Engl). 2012; 125(19): 3440-3444, indexed in Pubmed: 23044303.

68. Bobjer J, Katrinaki M, Dermitzaki E, et al. Serum chemerin levels are negatively associated with male fertility and reproductive hormones. Hum Reprod. 2018; 33(12): 2168-2174, doi: 10.1093/humrep/dey310, indexed in Pubmed: 30304526.

69. Alshaikh EM, Omar UM, Alsufiani HM, et al. The potential influence of hyperthyroidism on circulating adipokines chemerin, visfatin, and omentin. Int J Health Sci (Qassim). 2019; 13(2): 44-47, indexed in Pubmed: 30983945

70. Zeng J, Li K, Gong Y, et al. Association of pro-inflammatory cytokines with QCT-measured bone mineral density and its gender difference in a Chinese population - a pilot study. Endokrynol Pol. 2019; 70(3): 248-254 doi: 10.5603/EP.a2019.0014, indexed in Pubmed: 30845341.

71. Głogowska-Szeląg J, Kos-Kudła B, Marek B, et al. Assessment of selected adipocytokines in obese women with postmenopausal osteoporosis. Endokrynol Pol. 2019; 70(6): 478-483, doi: 10.5603/EP.a2019.0043, indexed in Pubmed: 31566247. 